\title{
Removal of Toxic Mercury from Petroleum Oil by Newly Synthesized Molecularly-Imprinted Polymer
}

\author{
Nor Ain Shahera Khairi ${ }^{1}$, Nor Azah Yusof ${ }^{1,2, *}$, Abdul Halim Abdullah ${ }^{1}$ and \\ Faruq Mohammad ${ }^{2, *}$
}

1 Department of Chemistry, Faculty of Science, Universiti Putra Malaysia, 43400 Serdang, Selangor, Malaysia; E-Mails: khairinorainshahera@yahoo.com (N.A.S.K.); halim@upm.edu.my (A.H.A.)

2 Institute of Advanced Technology, Universiti Putra Malaysia, 43400 Serdang, Selangor, Malaysia

* Authors to whom correspondence should be addressed;

E-Mails: azahy@upm.edu.my (N.A.Y.); farooqm1983@gmail.com (F.M.);

Tel.: +6-03-8946-6782 (N.A.Y.); +6-03-8946-7502 (F.M.); Fax: +6-03-8943-5380 (N.A.Y.).

Academic Editor: Andreas Taubert

Received: 17 February 2015 / Accepted: 16 April 2015 / Published: 8 May 2015

\begin{abstract}
In recent years, molecularly-imprinted polymers (MIPs) have attracted the attention of several researchers due to their capability for molecular recognition, easiness of preparation, stability and cost-effective production. By taking advantage of these facts, $\mathrm{Hg}$ (II) imprinted and non-imprinted copolymers were prepared by polymerizing mercury nitrate stock solution (or without it) with methacrylic acid (MAA), 2-hydroxyl ethyl methacrylate (HEMA), methanol and ethylene glycol dimethacrylate (EGDMA) as the monomer, co-monomer solvent (porogen) and cross-linker, respectively. Thus, the formed $\mathrm{Hg}$ (II) imprinted polymer was characterized by using Fourier transform infrared spectroscopy (FTIR), field emission scanning electron microscopy (FESEM), Brunauer, Emmett and Teller (BET) and thermal gravimetric analysis (TGA). The separation and preconcentration characteristics of $\mathrm{Hg}$ (II) imprinted polymer were investigated by solid phase extraction (SPE) procedures, and an optimal $\mathrm{pH}$ of 7 was investigated as ideal. The specific surface area of the $\mathrm{Hg}(\mathrm{II})$ imprinted polymer was found to be $19.45 \mathrm{~m}^{2} / \mathrm{g}$ with a size range from 100 to $140 \mu \mathrm{m}$ in diameter. The maximum adsorption capacity was observed to be $1.11 \mathrm{mg} / \mathrm{g}$ of $\mathrm{Hg}$ (II) imprinted beads with $87.54 \%$ removal of $\mathrm{Hg}$ (II) ions within the first $5 \mathrm{~min}$. The results of the study therefore confirm that the $\mathrm{Hg}$ (II) imprinted polymer can be used multiple times without significantly losing its adsorption capacity.
\end{abstract}


Keywords: molecularly-imprinted polymer; cysteine complex; mercury removal; petroleum oil; Freundlich isotherm

\section{Introduction}

Mercury $(\mathrm{Hg})$ is classified as one of the most toxic heavy metals on Earth, where it can be adsorbed through the skin, oral routes or by inhalation and exhibit adverse reactions on human health [1]. This further leads to a variety of health defects, including neurological, renal, respiratory, immune, dermatologic, reproductive and developmental neurotoxicity [2]. According to WHO guidelines, the mercury limitation is restricted to $1 \mu \mathrm{g} / \mathrm{L}$ in water for total mercury and $1 \mu \mathrm{g} / \mathrm{m}^{3}$ in air. In addition, the WHO estimated a tolerable concentration of $0.2 \mu \mathrm{g} / \mathrm{m}^{3}$ for long-term inhalation exposure to elemental mercury vapor and confined for a tolerable intake of $2 \mu \mathrm{g} / \mathrm{kg}$ body weight per day [3]. Furthermore, from the understanding of the toxicity effects, mercury and its compounds are listed in almost all classes of priority pollutants, where different guidelines and regulations have been set on limiting their levels in water, soil, sediments and in the environment [4].

According to the U.S. EPA 1997, combusted hydrocarbon was classified as one of the major anthropogenic sources of mercury emissions to the atmosphere in the U.S. Besides this, aquatic mercury contamination is caused by liquid discharges from petroleum refineries and petrochemical plants surrounding the rivers, where mercury is identified to be present as one of the most common heavy metals in petroleum oil [5]. In many forms of crude oils, a variety of mercury-containing species are found to be present, including elemental mercury, $\mathrm{Hg}$ (I) compounds, $\mathrm{Hg}$ (II) compounds and a combination thereof [6]. The presence of these elements can cause detrimental effects, as they pose significant product quality, environmental and safety issues. Furthermore, the consequences of mercury in feeds on processing systems includes the degradation of equipment parts, poisoning of catalysts, toxic waste generation and increased risk of the health and safety of workers. All of these factors can directly or indirectly be responsible for a reduction in the quality of the final hydrocarbon products [7].

Chemical adsorption, gas stripping and chemical precipitation methods are currently being used for removing mercury from crudes and other hydrocarbon liquids prior to their processing in order to avoid the problems of poisoning. Mercury removal with sorbent beds is a method used to scavenge the mercury from gas and liquid hydrocarbon streams. Gas phase treatment systems primarily consist of sulfur impregnated carbon, metal sulfide on carbon or alumina and regenerative molecular sieves. As for the hydrocarbon liquid streams, the systems consist of iodide-impregnated carbon [8], metal sulfide on carbon or alumina, a mol-sieve amalgam system and a two-step processing consisting of hydrogenation conversion catalyst followed by metal sulfide reaction with elemental mercury. All of the commercialized methods have both advantages, as well as disadvantages, depending on the feed composition and stream location. For example, mol-sieve amalgamation sorbents do not operate at high efficiencies if the organic form of mercury is present in a significant concentration. Other than that, sulfur-impregnated carbon is soluble in liquid hydrocarbon and cannot be used in process locations $[9,10]$. 
In recent years, the molecular imprinting technique has attracted considerable interest in many areas of science, such as in physics, chemistry, biochemistry and biotechnology, owing to its high degree of selectivity and affinity towards the target molecules [11]. The molecularly-imprinted polymer (MIP) processed by the molecular imprinting technique can be described as the synthetic polymeric materials having specific recognition sites that are complementary in shape, size and functional groups with regards to the template molecule [12]. This unique ability can recognize the template molecule used in the imprinting process, even in the presence of compounds having a similar structure and functionality to the template [13]. The MIPs tend to be simple and inexpensive to prepare. The MIPs also offer several advantages, including high mechanical strength, resistance to elevated temperatures and pressure and stability in the presence of extreme acidic, basic, metal ionic and organic solvent conditions [14].

Based on the selection of features and advantages offered by the molecular imprinting technique, the aim of the present work is to introduce a suitable MIP probe that can be useful for the selective trapping of mercury and its compounds from a mercury removal system. For that, the synthesis method we used involves free radical or chain growth polymerization, as these are the most commonly applied methods in industries for the conversion of monomers into polymer. We have selected cysteine monomer to form a polymerized complex in the presence of other organic molecules, and the reason for selecting cysteine is that it contains some electronegative groups, such as $-\mathrm{NH}_{2},-\mathrm{SH}$ and $-\mathrm{COOH}$, in its structure. These groups with their lone pair of electrons can easily form the electrostatic and van der Waals forces of attractions with the electropositive $\mathrm{Hg}$ compounds, and in this way, the adsorption can be easier, stronger and stable without any leaching [15]. Thus, synthesized MIP was tested for its mercury trapping capacity against various parameters, including the $\mathrm{pH}$, dosage, sorption kinetics, sorption isotherms, reusability and selectivity. From the analysis of results and by consideration of the versatility, it is indicated that a high level of selectivity and recognition can be achieved with our MIP, which further confirms the future use of MIPs as a promising sorbent material in mercury removal systems.

\section{Results and Discussion}

\subsection{Characterization Studies}

\subsubsection{FTIR}

The Fourier transform infrared (FTIR) spectra recorded by making use of the universal attenuated total reflectance (UATR) method for the cysteine complex along with the $\mathrm{Hg}(\mathrm{II})$-cysteine complex (MIP) are shown in Figure 1. From the figure, the spectrum of the cysteine complex showing the characteristic absorbance peak at $2588 \mathrm{~cm}^{-1}$ can be ascribed to $-\mathrm{SH}$ stretching vibration. It is obvious that there is no peak observed in the $-\mathrm{SH}$ region for MIP, indicating the absence of the - SH group in the polymer form. This confirms the complete polymerization of the $-\mathrm{SH}$ group in the cysteine complex with the $\mathrm{Hg}$ (II) template. The sulfhydryl groups can donate the lone pair of electrons to the empty orbit of metal ions alone. Similarly, the observation of a peak around $1744 \mathrm{~cm}^{-1}$ related to the $-\mathrm{C}=\mathrm{O}$ group in the cysteine complex was found at $1732 \mathrm{~cm}^{-1}$ in MIP, confirming the persistence of the bonding without any further modifications. Furthermore, the observation of a sharp peak in the 
fingerprint region of around $1150 \mathrm{~cm}^{-1}$ in both samples can be attributed to the $\mathrm{C}-\mathrm{N}$ and $\mathrm{C}-\mathrm{S}$ stretching vibrations of the groups $\left(-\mathrm{NH}_{2}\right.$ and $\left.-\mathrm{SH}\right)$ available in cysteine. Further, the appearance and persistence of peaks in both the cysteine complex and MIP confirm the maintenance of the cysteine skeleton without much alteration, even in the MIP $\mathrm{Hg}(\mathrm{II})$-cysteine complex [16].

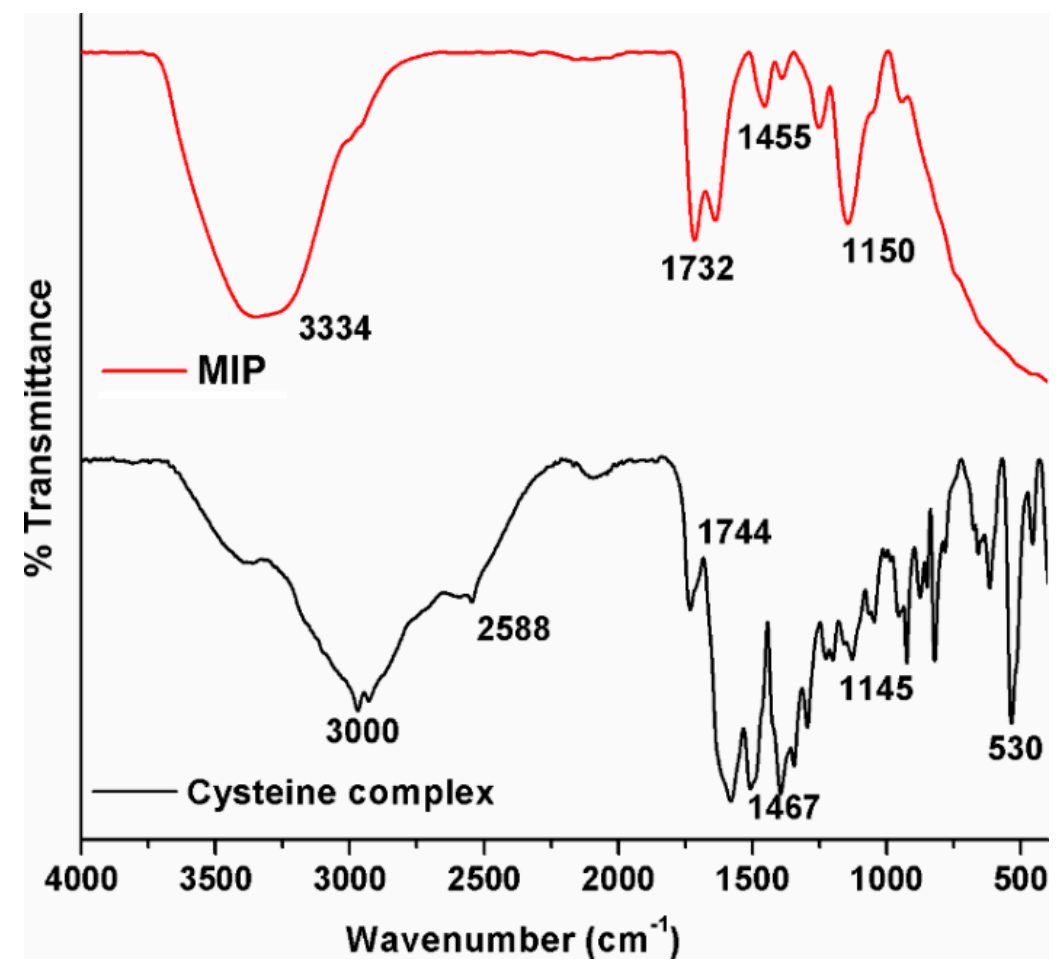

Figure 1. Comparison of FTIR spectra of the cysteine complex and the molecularly-imprinted polymer (MIP) $\mathrm{Hg}(\mathrm{II})$-cysteine complex.

\subsubsection{FE-SEM Analysis}

The structural morphology of MIP and non-imprinted polymer (NIP) beads is exemplified by the electron micrographs in Figure 2A,B. From the figure, all of the beads seem to possess a spherical shape, and the spots of MIP exhibit large particles packed together with a rough surface morphology (Figure 2A). However, the NIP morphology seems to contain densely packed particles with a smoother surface (Figure 2B), and this may be due to the fact that no specific binding sites have been created by the mercury template. Porosity is a very important factor, as it can change the surface area of the materials by creating new binding sites that are responsible for the selective removal of $\mathrm{Hg}$ (II) ions from solutions by means of trapping them [15]. 

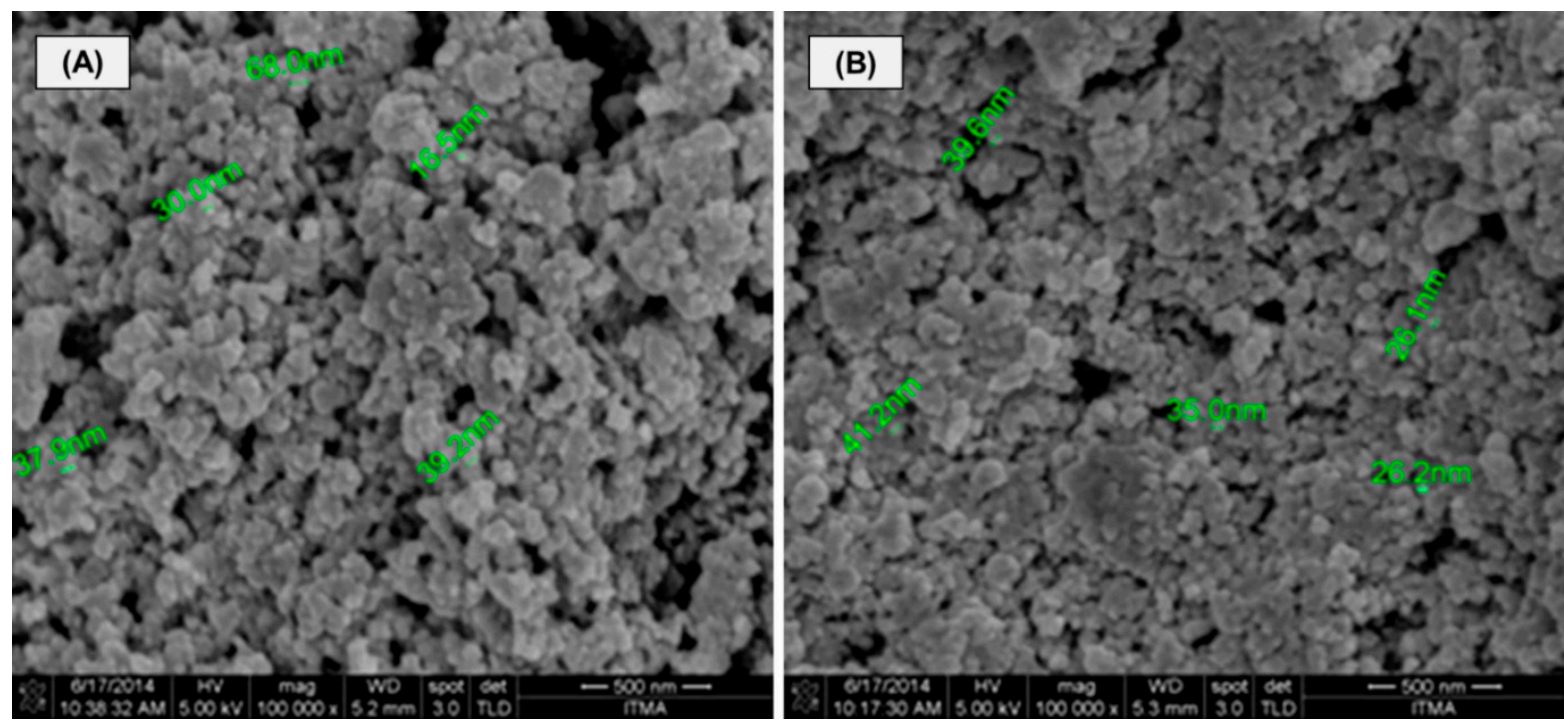

Figure 2. FE-SEM images of the Hg(II)-imprinted polymer (MIP) (A) and the non-imprinted polymer (NIP) (B) (magnification: 100,000×). Scale bar $=500 \mathrm{~nm}$.

\subsubsection{Thermal Stability}

The thermal analyses for the monomer, MIP and NIP were performed to understand the stability at various temperatures and to investigate the stages of decomposition (Figure 3). In the measurement process, the samples were heated from 35 to $1000{ }^{\circ} \mathrm{C}$ at a heating rate of $10{ }^{\circ} \mathrm{C} / \mathrm{min}$ in a $\mathrm{N}_{2}$ atmosphere. From the figure, one can see a similar kind of degradation pattern between MIP and NIP. The monomer methacrylic acid (MAA) started to decompose at $T_{\mathrm{i}}$ of $145{ }^{\circ} \mathrm{C}$, and the final decomposition $T_{\mathrm{f}}$ is observed at $197{ }^{\circ} \mathrm{C}$. However, the initial compositions $T_{\mathrm{i}}$ of MIP and NIP are observed at 192 and $196{ }^{\circ} \mathrm{C}$ and final decompositions $T_{\mathrm{f}}$ at 671 and $601{ }^{\circ} \mathrm{C}$, respectively. From the comparison of data of MIP and NIP against the monomer, it is indicated that the MIP and NIP have higher thermal stabilities due to the formation of a complex hybrid structure by means of polymerization. Within MIP and NIP, the final decomposition temperature of MIP is relatively higher than the corresponding NIP, indicating the stability of the MIP template at quite higher temperatures [17].

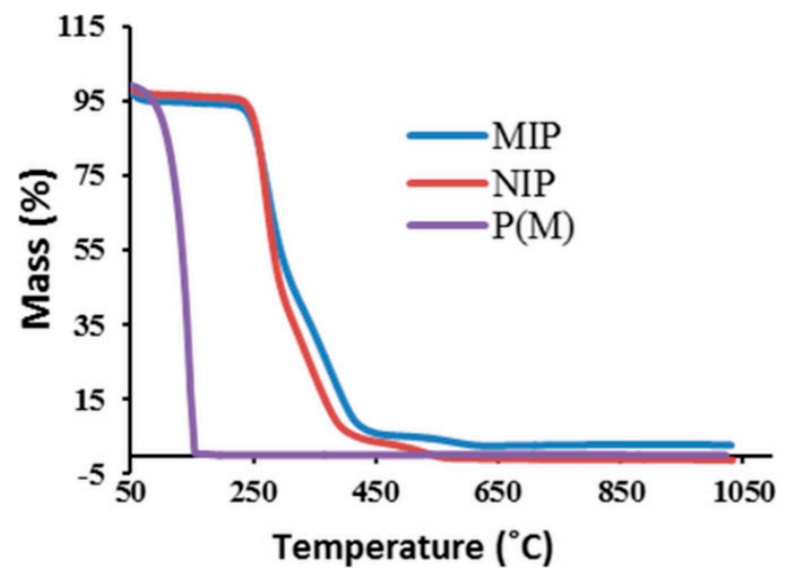

Figure 3. Studies of thermal gravimetric analysis (TGA) for the monomer $(\mathrm{P}(\mathrm{M}))$, molecularly-imprinted polymers (MIP), non-imprinted polymer (NIP). 


\subsection{Effect of $p H$}

The effect of $\mathrm{pH}$ on $\mathrm{Hg}(\mathrm{II})$ sorption towards MIP and NIP was studied in the $\mathrm{pH}$ range from 3.0 to 9.0, and the results are presented in Figure 4. It can be seen from the figure that the binding capacity seems to be increased with an increase of $\mathrm{pH}$ for both materials. For the $\mathrm{pH}$ in the range of 3.0-4.0, the sorption was found to be low, owing to the high concentration and mobility of the $\mathrm{H}^{+}$ions that get preferentially adsorbed onto the lone pairs of the MIP in comparison with $\mathrm{Hg}$ (II) ions [18]. Further, the sorption increased rapidly after $\mathrm{pH}$ 5.0, but the increasing rate for the NIP is slow compared to MIP. At a high $\mathrm{pH}$ value of $>7.0$, the binding capacity decreased due to the precipitation of the metal hydroxide and its quick decomposition further to oxide in both polymers [19]. Overall, the graph of NIP shows low binding capacity compared against the MIP due to the non-specific interaction between $\operatorname{He} \mathrm{Hg}$ (II) ions and the polymer matrix. Furthermore, as seen from the figure, the optimum $\mathrm{pH}$ value for the sorption of $\mathrm{Hg}$ (II) from aqueous solution was obtained to be at $\mathrm{pH} 7.0$, and therefore, the $\mathrm{pH}$ was adjusted to 7.0 for all of the subsequent studies.

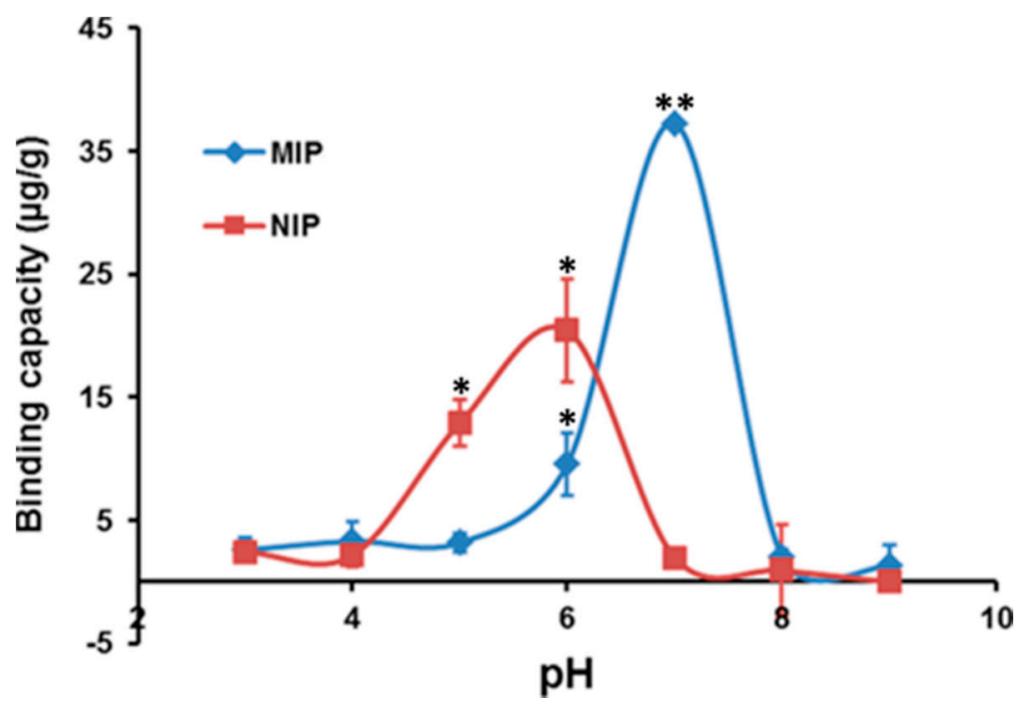

Figure 4. The effect of $\mathrm{pH}$ towards the sorption of $\mathrm{Hg}(\mathrm{II})$ for the MIP and NIP material (studies were carried out by taking $10 \mathrm{mg}$ of MIP and NIP at a $25^{\circ} \mathrm{C}$ ). The results are expressed as the mean $\pm \mathrm{SD}$ of the individual experiments; $*$ and ** indicate the significance at $p<0.05$ and $p<0.01$ versus the controls.

\subsection{Effect of Dosage on MIP}

The dependence of the mass of sorbents (dosage) on the binding capacity of $\mathrm{Hg}$ (II) was studied by varying the amount of MIP from 5.0 to $100.0 \mathrm{mg}$, and the results are shown in Figure 5. From the figure, the graph shows that the percentage removal of $\mathrm{Hg}(\mathrm{II})$ has increased with regards to an increase in the mass of sorbents. This is due to the fact that the increased dosage of MIP eventually increased the binding sites that are available for the sorption of $\mathrm{Hg}(\mathrm{II})$ onto the MIP's surface [20]. 


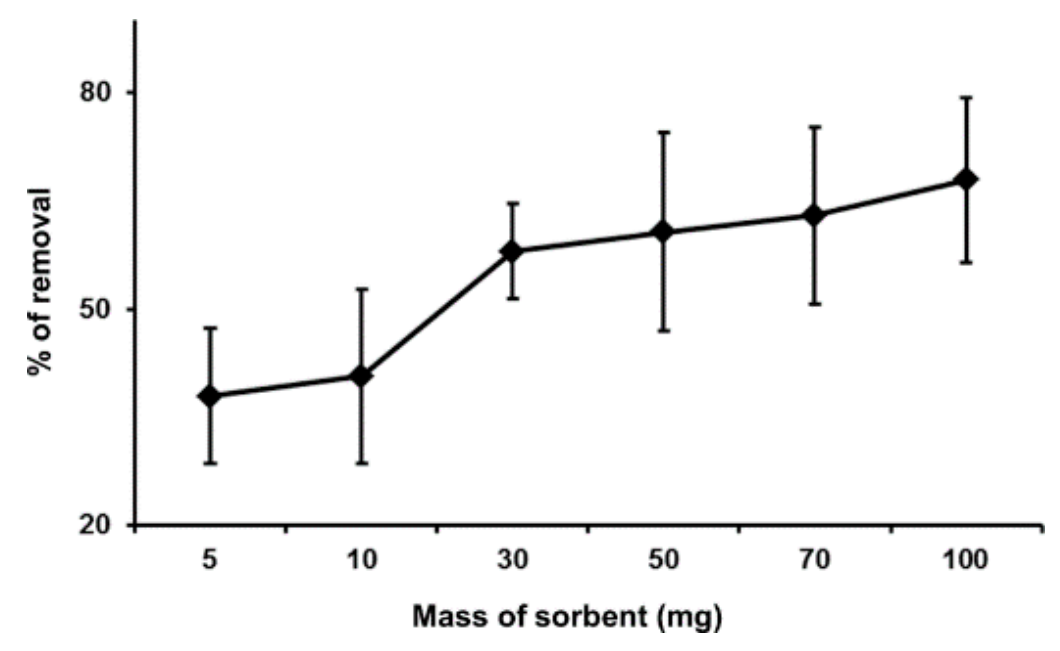

Figure 5. Effect of dosage on the percentage removal of $\mathrm{Hg}(\mathrm{II})$ (conditions: $10 \mathrm{~mL}$ of $200 \mathrm{ppb}$ of $\mathrm{Hg}(\mathrm{II})$, at $\mathrm{pH} 7$ and $25^{\circ} \mathrm{C}$, contact time of $10 \mathrm{~s}$ ).

\subsection{Adsorption Isotherm}

Equilibrium data, also known as the adsorption isotherm, are the basic requirement for designing an adsorption system. The sorption isotherm was measured for $\mathrm{Hg}$ (II) using MIP by varying the initial concentration of $\mathrm{Hg}$ (II) solution, and the results are shown in Figure 6. From the analysis of the results, a significant sorption capacity was observed at $4.46 \mathrm{mg} / \mathrm{g}$. In this work, the equilibrium data for $\mathrm{Hg}$ (II) on MIP was modeled with the Langmuir and Freundlich model [21].

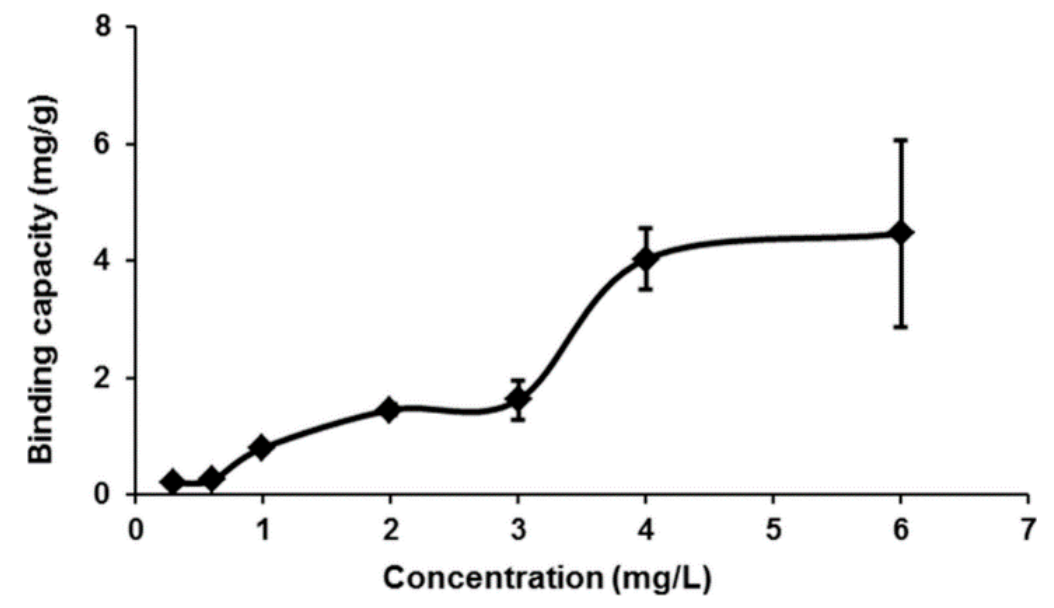

Figure 6. Effect of equilibrium $\mathrm{Hg}(\mathrm{II})$ concentration on the adsorption of $\mathrm{Hg}(\mathrm{II})$ ions on MIP (conditions: total volume of $10 \mathrm{~mL}, 10 \mathrm{mg}$ of MIP beads, $\mathrm{pH} \mathrm{7}$, temperature $25^{\circ} \mathrm{C}$, contact time $10 \mathrm{~s})$.

The Langmuir model may be represented in a linear equation form as below:

$$
\frac{C_{e}}{q_{e}}=\frac{C_{e}}{Q_{m}}+\frac{1}{b Q_{m}}
$$

where $C_{e}$ is the equilibrium concentration $(\mathrm{mg} / \mathrm{L}), q_{e}$ is the amount of $\mathrm{Hg}(\mathrm{II})$ adsorbed at equilibrium (mg/g) and $Q_{m}$ and $b$ are Langmuir constants, which are related to the sorption capacity and energy of sorption, respectively. The plot of $C_{e} / q_{e}$ against $C_{e}$ was used to validate the Langmuir isotherm. 
The Freundlich isotherm is an exponential equation and therefore assumes that as the sorbate concentration increases, the concentration of sorbate on the adsorbent surface also gets increased. The frequently used linear equation for the Freundlich isotherm is shown below:

$$
\log q_{\mathrm{e}}=\log K_{\mathrm{f}}+\frac{1}{\mathrm{n}} \log C_{e}
$$

where $K_{\mathrm{f}}$ is the intercept showing the sorption capacity of the sorbents and $1 / \mathrm{n}$ is the slope showing the variation of the sorption with concentration.

Both Langmuir and Freundlich plots for the sorption of $\mathrm{Hg}(\mathrm{II})$ are shown in Figure 7a,b, and the related constants are given in Table 1. From the results, the value of the correlation coefficient for the Freundlich plot is high $\left(R^{2}=0.9551\right)$ compared with the Langmuir plot $\left(R^{2}=0.1025\right)$. The calculated value of $K_{\mathrm{f}}$ for the Freundlich model is comparable to the experimental value $q_{\mathrm{e}}$, and thus, it can be concluded that the sorption of $\mathrm{Hg}(\mathrm{II})$ onto MIP obeys the Freundlich model. The Freundlich isotherm gives the relationship of equilibrium between the liquid and solid phases based on the multilayer adsorption (heterogeneous surface). The Freundlich isotherm explains this better, probably due to the multiple interaction and adsorption that occurs on multiple layers of the adsorbates. Besides this, the Freundlich model has been shown to be generally applicable to most of the non-covalently-imprinted polymers [22,23].

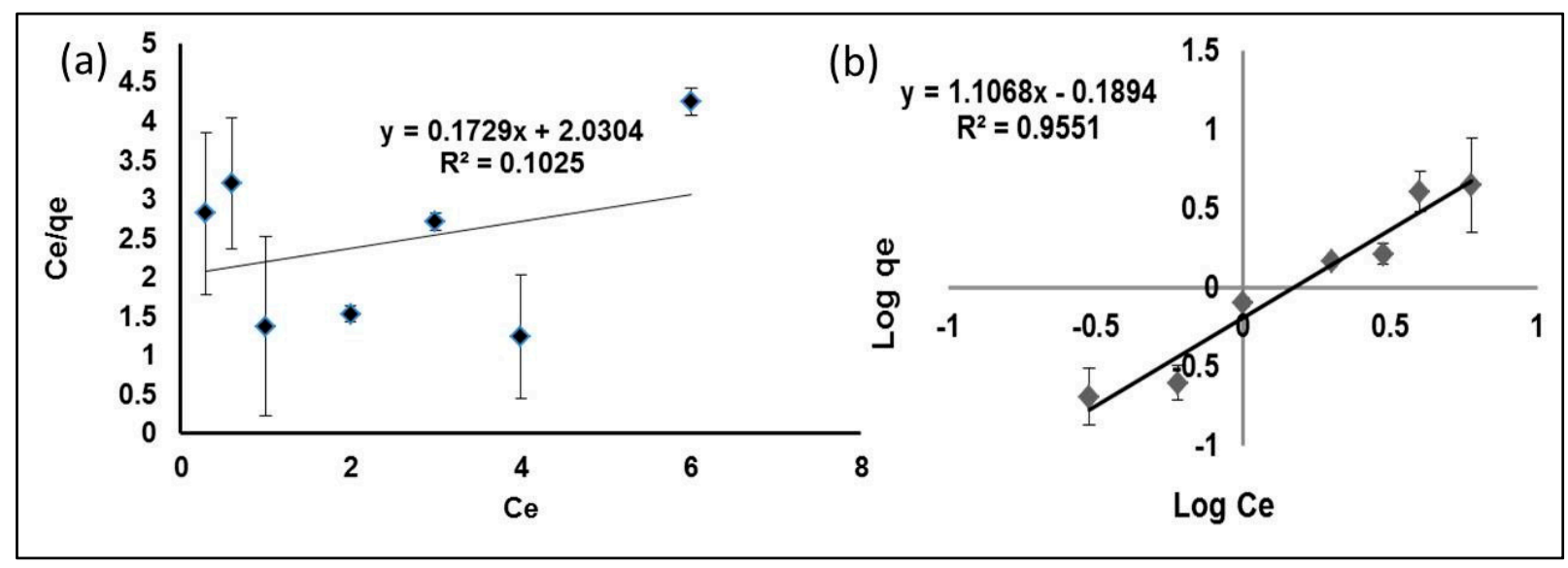

Figure 7. Langmuir (a) and Freundlich (b) plots for the sorption of $\mathrm{Hg}(\mathrm{II})$ by MIP.

Table 1. Langmuir and Freundlich adsorption constants for the MIP beads.

\begin{tabular}{ccccccc}
\hline Experimental & \multicolumn{3}{c}{ Langmuir Constant } & \multicolumn{3}{c}{ Freundlich Constant } \\
\cline { 2 - 7 }$\left(\boldsymbol{q}_{\mathrm{e}}=\mathbf{m g} / \mathbf{g}\right)$ & $\boldsymbol{Q}_{\mathbf{m}}(\mathbf{m g} / \mathbf{g})$ & $\boldsymbol{b}_{\mathbf{L}}(\mathbf{L} / \mathbf{m g})$ & $\boldsymbol{R}^{\mathbf{2}}$ & $\boldsymbol{K}_{\mathrm{f}}(\mathbf{m g} / \mathbf{g})$ & $\mathbf{1} / \mathbf{n}(\mathbf{L} / \mathbf{m g})$ & $\boldsymbol{R}^{\mathbf{2}}$ \\
\hline 4.46 & 5.7837 & 0.0505 & 0.1025 & 0.6465 & 1.1068 & 0.9551 \\
\hline
\end{tabular}

\subsection{Adsorption Kinetics}

To determine the rate of loading of $\mathrm{Hg}(\mathrm{II})$ on the MIP, the binding capacity as a function of time was measured and is shown in Figure 8. From the figure, the $\mathrm{Hg}$ (II) sorption process seems to be rapid in the first few seconds and rather slow while approaching an equilibrium stage. The maximum adsorption capacity occurred over a 30-min period investigated to be around $1.132 \mathrm{mg} / \mathrm{g}$, which is 
equivalent to about an $89.0 \%$ sorption, i.e., confirming the higher sorption capacity in a short period of time.

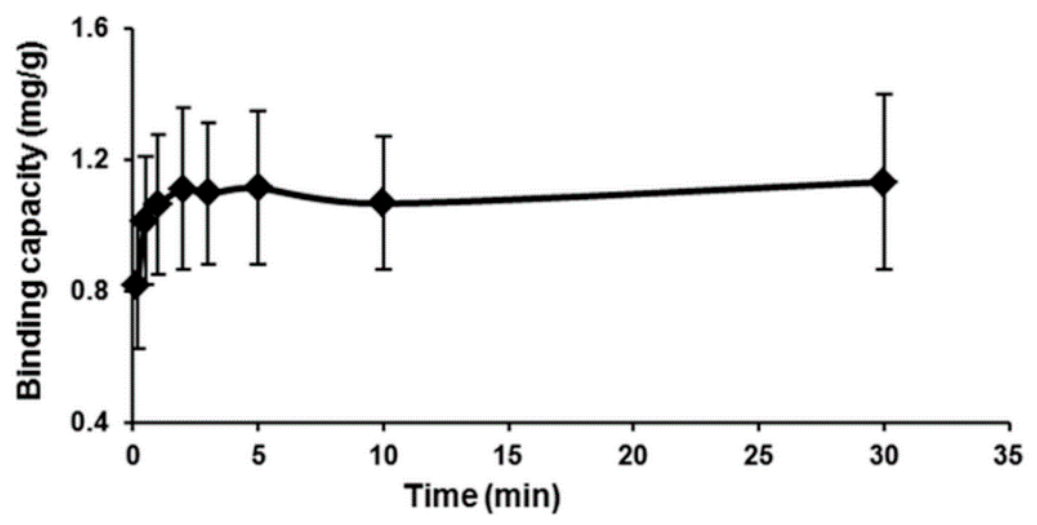

Figure 8. Time-dependent adsorption of $\mathrm{Hg}(\mathrm{II})$ ions on the MIP beads (conditions: $50 \mathrm{~mL}$ of $2 \mathrm{mg} / \mathrm{L} \mathrm{Hg}(\mathrm{II})$ ions solution, $50 \mathrm{mg}$ polymer, at $\mathrm{pH} 7$ and $25^{\circ} \mathrm{C}$ ).

The sorption kinetic data of $\mathrm{Hg}(\mathrm{II})$ were analyzed using Langergen's first order rate model, and the equation involved is shown below [24]:

$$
\ln \left(q_{\mathrm{e}}-q_{\mathrm{t}}\right)=\ln \left(q_{\mathrm{e}}\right)-K_{\mathrm{l}} t
$$

where $K_{1}\left(\mathrm{~min}^{-1}\right)$ is the rate constant of pseudo-first order sorption, $q_{\mathrm{t}}$ denotes the amount of $\mathrm{Hg}$ (II) sorption $(\mathrm{mg} / \mathrm{g})$ at times $\mathrm{t}(\mathrm{min})$ and $q_{\mathrm{e}}$ denotes the amount of $\mathrm{Hg}(\mathrm{II})$ sorption $(\mathrm{mg} / \mathrm{g})$ at equilibrium.

In addition, the sorption kinetic data for $\mathrm{Hg}(\mathrm{II})$ was also analyzed with the pseudo-second order equation based on the adsorption equilibrium capacity, as shown below [25]:

$$
\frac{t}{q_{\mathrm{t}}}=\frac{1}{K_{2} q_{\mathrm{e}}^{2}}+\frac{t}{q_{\mathrm{e}}}
$$

The plot $t / q_{\mathrm{t}}$ versus $\mathrm{t}$ should give a straight line if the second order kinetics is applicable, and the values $q_{\mathrm{e}}$ and $K_{2}$ can be calculated from the slope and the intercept of the plot, respectively. This model is more likely to predict the kinetic behavior of sorption, with chemical sorption being the rate-controlling step [26].

The pseudo-first and second order kinetics towards the adsorption of $\mathrm{Hg}$ (II) on MIP are shown in Figure 9a,b. From the figure, the linear plot of $\ln \left(q_{\mathrm{e}}-q\right)$ versus $t$ for the pseudo-first order kinetics (Figure 9a) shows a low correlation coefficient $\left(R^{2}=0.0341\right)$. Moreover, Table 2 shows a large difference of experimental and calculated sorption capacities indicated for a poor pseudo-first order fit to the experimental data. However, from Figure 9b, the pseudo-second order model was likely a straight line having a high correlation coefficient $\left(R^{2}=0.999\right)$. The values of rate constants summarized in Table 2 provide the information that the theoretical value of $q_{\mathrm{e}}$ (cal) was closer to the experimental $q_{\mathrm{e}}(\exp )$ value for the pseudo-second order. From the analysis of the results, it is evident, therefore, that the pseudo-second order kinetic model provided a good correlation for the sorption of $\mathrm{Hg}(\mathrm{II})$ onto MIP [17]. 

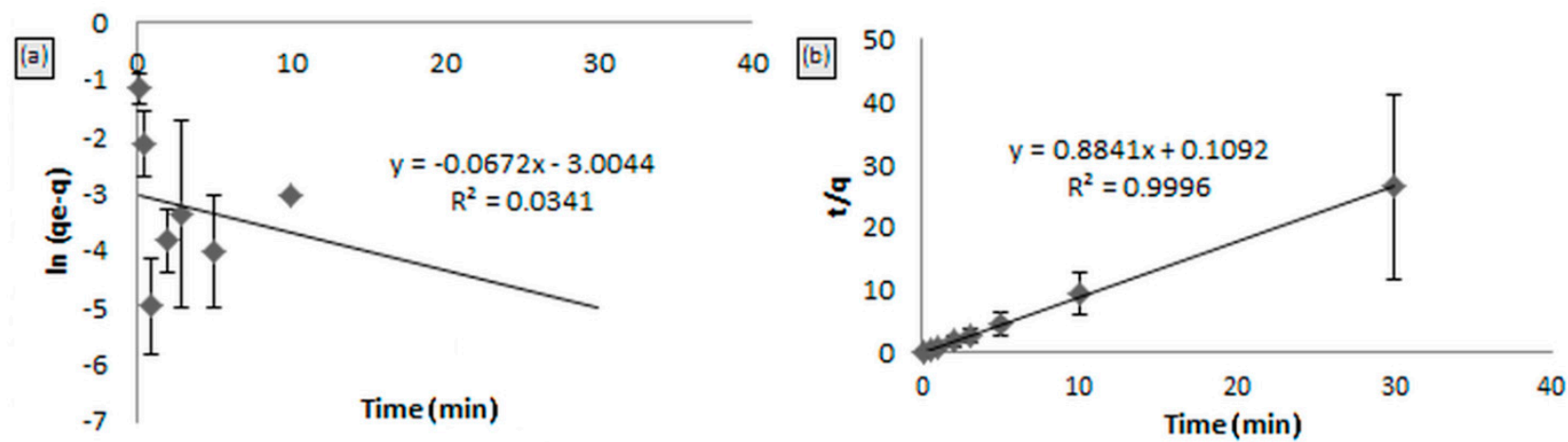

Figure 9. Kinetic model: (a) pseudo-first order kinetic model and (b) pseudo-second order kinetic model for MIP beads.

Table 2. The first and second order kinetic constants for the MIP beads.

\begin{tabular}{ccccccc}
\hline \multirow{2}{*}{$\begin{array}{c}\text { Fxperimental } \\
\boldsymbol{q}_{\mathrm{e}}(\mathbf{e x p})\end{array}$} & \multicolumn{3}{c}{ First Order } & \multicolumn{3}{c}{ Second Order } \\
\cline { 2 - 7 } & $\boldsymbol{K}_{\mathbf{1}}\left(\mathbf{m i n}^{-\mathbf{1}}\right)$ & $\boldsymbol{q}_{\mathrm{e}}(\mathbf{c a l c})(\mathbf{m g} / \mathbf{g})$ & $\boldsymbol{R}^{\mathbf{2}}$ & $\boldsymbol{K}_{\mathbf{2}}\left(\mathbf{m g} / \mathbf{g} \cdot \mathbf{m i n}^{-\mathbf{1}}\right)$ & $\left.\boldsymbol{q}_{\mathrm{e}}(\mathbf{c a l c}) \mathbf{( m g} / \mathbf{g}\right)$ & $\boldsymbol{R}^{\mathbf{2}}$ \\
\hline 1.132 & 0.0672 & 0.0496 & 0.0341 & 7.1577 & 1.074 & 0.9996 \\
\hline
\end{tabular}

\subsection{Selectivity Studies}

The competitive sorption of $\mathrm{Hg}(\mathrm{II}) / \mathrm{Zn}$ (II), $\mathrm{Hg}$ (II)/Cd(II) and $\mathrm{Hg}(\mathrm{II}) / \mathrm{Pb}$ (II) from the mixtures of all respective metals was conducted using MIP and NIP. $\mathrm{Zn}(\mathrm{II})$ and $\mathrm{Cd}(\mathrm{II})$ were chosen as competitive metals for $\mathrm{Hg}(\mathrm{II})$, because of their similar atomic radii, while $\mathrm{Pb}$ (II) was chosen because of a similar period number, which means that they both have six occupied energy shells. Further, the distribution and selectivity coefficient of $\mathrm{Hg}$ (II) with respect to other metals were calculated using the equation shown below [27].

$$
K_{\mathrm{d}}=\frac{\left(C_{\mathrm{i}}-C_{\mathrm{f}}\right) V}{M}
$$

where $K_{\mathrm{d}}, C_{\mathrm{i}}$ and $C_{\mathrm{f}}$ represent the distribution coefficient and initial and final solution concentrations $(\mathrm{mg} / \mathrm{L})$, respectively. $V$ is the volume of the solution $(\mathrm{L})$, and $M$ is the mass of the sorbents $(\mathrm{g})$. The selectivity coefficient of the binding of an ion with the competitor ions can be obtained from the equilibrium data according to Equation (7).

$$
K=\frac{K_{\mathrm{d}}(\text { template metal })}{K_{\mathrm{d}}(\text { interferent metal })}
$$

where $K$ is the selectivity coefficient of interfering metals. A comparison of the $K$ value of the imprinted polymer with those metal ions allows an estimation of the effect of imprinting on selectivity. In order to evaluate the imprinting effect, a relative selectivity coefficient $K^{\prime}$ was defined as follows:

$$
K^{\prime}=\frac{K \text { (imprinted) }}{K \text { (non-imprinted) }}
$$

Table 3 summarizes the distribution coefficient $\left(K_{\mathrm{d}}\right)$, selectivity coefficient $k$ values of $\mathrm{Cd}(\mathrm{II})$, $\mathrm{Zn}(\mathrm{II})$ and $\mathrm{Pb}(\mathrm{II})$ with respect to $\mathrm{Hg}$ (II). From the table, the comparison of $K_{\mathrm{d}}$ values for $\mathrm{Hg}$ (II) with other competitive metals shows a high $K_{\mathrm{d}}$ value, while showing decreasing values for $\mathrm{Zn}(\mathrm{II}), \mathrm{Cd}(\mathrm{II})$ 
and $\mathrm{Pb}(\mathrm{II})$. The relative selectivity coefficient $K^{\prime}$ is an indicator for expressing the metal adsorption affinity of recognition sites to the imprinted $\mathrm{Hg}$ (II) ions [17]. These results show that the relative $K^{\prime}$ values for the $\mathrm{Hg}(\mathrm{II}) / \mathrm{Zn}(\mathrm{II}), \mathrm{Hg}(\mathrm{II}) / \mathrm{Cd}(\mathrm{II})$ and $\mathrm{Hg}(\mathrm{II}) / \mathrm{Pb}(\mathrm{II})$ are 2.03, 1.50 and 1.46, respectively, i.e., all of the values are higher than one. This proves that the presence of $\mathrm{Hg}$ (II) can be determined even with the existence of $\mathrm{Zn}(\mathrm{II}), \mathrm{Cd}(\mathrm{II})$ and $\mathrm{Pb}(\mathrm{II})$, which further provides evidence for the promising application of our synthesized MIP for the separation of $\mathrm{Hg}(\mathrm{II})$ ions.

Table 3. $K_{\mathrm{d}}, K$, and $K^{\prime}$ values of $\mathrm{Zn}(\mathrm{II}), \mathrm{Cd}(\mathrm{II})$ and $\mathrm{Pb}(\mathrm{II})$ with respect to $\mathrm{Hg}(\mathrm{II})$.

\begin{tabular}{cccccc}
\hline \multirow{2}{*}{ Metal Ion } & \multicolumn{2}{c}{ MIP } & \multicolumn{2}{c}{ NIP } & \multirow{2}{*}{$\boldsymbol{K}^{\prime}$} \\
\cline { 2 - 5 } & $\boldsymbol{K}_{\mathbf{d}}$ & $\boldsymbol{K}$ & $\boldsymbol{K}_{\mathbf{d}}$ & $\boldsymbol{K}$ & \\
\hline $\mathrm{Hg}(\mathrm{II})$ & 0.87 & - & 0.66 & - & - \\
\hline $\mathrm{Zn}(\mathrm{II})$ & 0.43 & 2.05 & 0.66 & 1.00 & 2.03 \\
$\mathrm{Cd}(\mathrm{II})$ & 0.54 & 1.60 & 0.62 & 1.07 & 1.50 \\
$\mathrm{~Pb}(\mathrm{II})$ & 0.04 & 22.52 & 0.04 & 15.42 & 1.46 \\
\hline
\end{tabular}

\subsection{Sorption of $\mathrm{Hg}(\mathrm{II})$ from Petroleum Oil}

The sorption of $\mathrm{Hg}$ (II) was carried out in real samples, which are sludge and crude petroleum oil. The samples were diluted with petroleum ether with 1:5 for crude oil samples and 1:15 for sludge sample. The MIP sorbents were treated with $2.0 \mathrm{~mL}$ methanol and $2.0 \mathrm{~mL}$ water before spiking with real samples. The samples were analyzed by a mercury analyzer, Nippon brand (Series Number NIC SP3D), and were done in HG solution Sdn. Bhd., Paka (Terengganu, Malaysia). Further, the samples were treated by using $10 \mathrm{~mL}$ of sample solutions in $10 \mathrm{mg}$ of MIP beads at room temperature. Figure 10a shows that the percentage removal of $\mathrm{Hg}$ (II) in the sludge sample getting increased rapid up to $93.8 \%$ within the first $2 \mathrm{~min}$ of treatment by the MIP particles. This fast absorption of MIP beads towards mercury ions is probably due to the higher electrostatic and geometric shape affinities between the $\mathrm{Hg}$ (II) ions and $\mathrm{Hg}$ ion cavities with those of the lone pair groups in the MIP microstructure. Similarly, during the removal of $\mathrm{Hg}$ (II) from the crude oil sample, the percentage removal of $\mathrm{Hg}$ (II) also seems to be increased from $17.4 \%$ (within $5 \mathrm{~s}$ ) to $29.8 \%$ after 2 min, as indicated by the graph shown in Figure $10 \mathrm{~b}$. It can also be seen from Figure 10a,b that the adsorption capacities are increasing with time, and the $\mathrm{Hg}$ (II) adsorption is fast during the first few seconds, until it reaches an equilibrium level that is achieved after $60 \mathrm{~s}$ for the sludge and $30 \mathrm{~s}$ for the crude oil sample. This represents the saturation of active binding cavities on the MIP particles, further confirming the potential usage of the synthesized MIP for the removal of $\mathrm{Hg}$ or its ions from the industrial samples.

Currently, the different approaches available for mercury removal include gas stripping, chemical precipitation, chemical adsorption and reverse osmosis. The gas stripping and reverse osmosis methods are relatively expensive, require heavy machinery and cannot be applied for pilot projects. The chemical precipitation, though, is a simple and easy method, but the use of toxic compounds, such as $\mathrm{H}_{2} \mathrm{SO}_{4}, \mathrm{Na}_{2} \mathrm{~S}_{2} \mathrm{O}_{3}$ or $\mathrm{I}_{2}$ limits its use for all samples on an industrial scale [8]. To overcome these limitations, we have followed the chemical adsorption technique for the selective removal of $\mathrm{Hg}$ (II) ions or its compounds by taking advantage of the lone pair electron groups of cysteine and thereby forming an MIP complex. Thus, the developed complex was found to be highly stable at elevated temperature conditions, as indicated by the thermal studies and further proved its efficiency by 
adsorbing the $\mathrm{Hg}$ (II) ions of $37.26 \mu \mathrm{g} / \mathrm{g}$ at a neutral $\mathrm{pH}$ of 7 . This property of the higher adsorption efficiency by the MIP at neutral $\mathrm{pH}$ is of utmost importance, as no other harsh conditions (acidic, basic or organic solvents) have to be maintained, and the reaction can be carried out with simple water (green approach), unlike other methods. Further, the selectivity efficiency of the MIP towards $\operatorname{Hg}$ (II) was confirmed by the presence of other competitive metal ions, such as $\mathrm{Cd}(\mathrm{II}), \mathrm{Zn}$ (II) and $\mathrm{Pb}(\mathrm{II})$. The testing of the material with other industrial samples isolated about $94 \%$ of $\mathrm{Hg}$ (II) from sludge and $30 \%$ from the crude oil samples during a fast time interval of $2 \mathrm{~min}$, confirming again its applicability for real-time analysis. We believe that our proposed method is superior compared to other mercury removal methods of gas stripping, reverse osmosis and chemical precipitation, where expensive handling, complex equipment and toxic solvents have to be used.

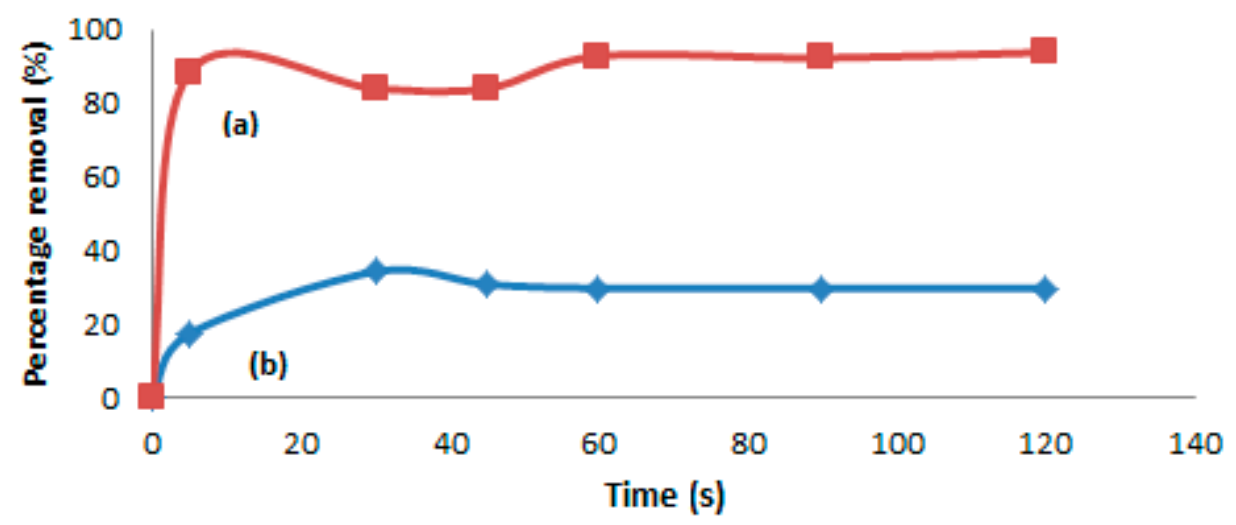

Figure 10. Comparison of the sorption capacities for (a) sludge and (b) crude oil samples.

\section{Experimental Section}

\subsection{Materials}

Methacrylic acid was purchased from Fluka (Steinheim, Germany). 2-hydroxyethyl methacrylate (HEMA), ethylene glycol dimethacrylate (EGDMA), (methacryloyl oxyethyl trimethyl) ammonium chloride, and L-cysteine were obtained from Sigma-Aldrich (St. Louis, MO, USA), stored at $4{ }^{\circ} \mathrm{C}$ until use. Benzoyl peroxide was obtained from $\mathrm{R} \& \mathrm{M}$ chemical (Essex, UK). All other chemicals and solvents used were of analytical grade and were used as received without any further purification.

\subsection{Preparation of Cysteine Complex}

The synthesis procedure used for the complexation of the cysteine ligand was adapted from elsewhere, but a small change of chemicals was applied [1]. Briefly, about $5 \mathrm{~g}$ of cysteine ligand and $0.2 \mathrm{~g}$ of sodium nitrate $\left(\mathrm{NaNO}_{2}\right)$ were dissolved in $30 \mathrm{~mL}$ of $\mathrm{K}_{2} \mathrm{CO}_{3}$ aqueous solution $(5 \% v / v)$ and then cooled to $0{ }^{\circ} \mathrm{C}$. To this solution, $4 \mathrm{~mL}$ of (methacryloyl oxyethyl) trimethyl ammonium chloride were added slowly under a nitrogen atmosphere. The resulting solution was magnetically stirred at room temperature for about $2 \mathrm{~h}$; at the end of this period, the $\mathrm{pH}$ of the solution was adjusted to 7.0 and further extracted by ethyl acetate. The aqueous phase was evaporated in a rotary evaporator and the residue (cysteine complex) was crystallized by using ethanol and ethyl acetate solvents. 


\subsection{Preparation of Cysteine Complex-Hg-Imprinted and Non-Imprinted Polymer}

The Hg-imprinted polymer was synthesized using the thermally-induced free radical polymerization method. For that, solid cysteine-complex ligand $(2.0 \mathrm{mmol})$ was added slowly to $50 \mathrm{~mL}$ of methanol and then treated with mercury nitrate, $\mathrm{Hg}\left(\mathrm{NO}_{3}\right)_{2}(1.0 \mathrm{mmol})$, solution at room temperature. The mixture was stirred for $20 \mathrm{~min}$ before $5 \mathrm{~mL}$ of this solution were pipetted into a borosilicate bottle, and MAA (6.0 mmol), HEMA (3.0 mmol), EGDMA $(30 \mathrm{mmol})$ and $0.1 \mathrm{~g}$ benzoyl peroxide were added. The mixture was stirred for $30 \mathrm{~min}$, followed by purging with nitrogen gas for $10 \mathrm{~min}$ before being sealed. Then, the mixture was transferred into a $70{ }^{\circ} \mathrm{C}$ water bath for polymerization, and the process was continued for $2 \mathrm{~h}$. After formation, the polymer was broken into large pieces before being crushed into small particles using a mortar and pestle. The MIP particles were washed with methanol/water solution $(60 / 40, v / v)$ for $24 \mathrm{~h}, 0.5 \%$ thiourea in $0.05 \mathrm{M} \mathrm{HCl}$ solution for $48 \mathrm{~h}$ at room temperature and cleaned with $0.1 \mathrm{M} \mathrm{HNO}_{3}$ in a magnetic stirrer for $3 \mathrm{~h}$. The non-imprinted polymer (NIP) was synthesized in a similar way, but in the absence of the template molecule, $\mathrm{Hg}\left(\mathrm{NO}_{3}\right)_{2}$.

\subsection{Characterization of MIP and NIP}

For the characterization of MIP and NIP, various instruments were used, which included the FTIR Perkin Elmer 1600 Spectrophotometer (Foster City, CA, USA) for the Fourier transform infrared (FTIR) spectroscopy, JEOL field emission scanning electron microscopy (FESEM) from JEM 1200 EX (Tokyo, Japan) for the surface morphology and an inductively-coupled plasma-mass spectrometer (ICP-MS) from Perkin Elmer Sciex ELAN DRC-e for the elemental analysis.

\subsection{Adsorption Studies}

The solid phase extraction (SPE) method was applied in order to study the adsorption of $\mathrm{Hg}$ (II) ions from aqueous solutions against the effects of the $\mathrm{pH}$, dosage, adsorption isotherm, kinetics and selectivity of the fabricated MIP and NIP. For that, the MIP and NIP particles were placed above the polyethylene frit inside the empty SPE cartridge and conditioned with $2 \mathrm{~mL}$ each of methanol and deionized water. Following the conditioning, the $\mathrm{Hg}$ (II) solution was allowed to pass through the cartridge at a flow rate of $0.25 \mathrm{~mL} / \mathrm{min}$, and the samples were collected after the completion of passing. The initial and final concentrations of $\mathrm{Hg}$ (II) were determined using the ICP-MS analysis, and the sorption capacity was calculated using Equation (8) shown below:

$$
q=\frac{\left(C_{\mathrm{o}}-C_{\mathrm{e}}\right) \times V}{M}
$$

where $q(\mathrm{mg} / \mathrm{g})$ is the amount of the total adsorption of $\mathrm{Hg}(\mathrm{II})$ and $C_{\mathrm{o}}$ and $C_{\mathrm{e}}$ are the initial and equilibrium concentrations of $\mathrm{Hg}(\mathrm{II})$ in solution $(\mathrm{mg} / \mathrm{L})$, respectively. $V(\mathrm{~L})$ is the volume of the solution, and $M(\mathrm{~g})$ is the weight of MIP.

The effect of the dosage of MIP and NIP particles on the sorption of $\mathrm{Hg}$ (II) was studied by varying the amounts of MIP and NIP (5, 10, 30, 50, 70 and $100 \mathrm{mg}$ ), while maintaining the concentration and volume of $\mathrm{Hg}$ (II) solution, $10.0 \mathrm{~mL}$ of $200 \mu \mathrm{L} / \mathrm{L} \mathrm{Hg}$ (II) of $1000 \mathrm{ppm}$ stock solution. The sorption isotherm was measured by using $10 \mathrm{mg}$ of MIP particles in $10 \mathrm{~mL}$ of $\mathrm{Hg}$ (II) solution with different concentrations $(0.3,0.6,1.0,2.0,3.0,4.0$ and $6.0 \mathrm{mg} / \mathrm{L})$. The adsorption kinetics were studied by using 
$50 \mathrm{mg}$ of MIP and $50 \mathrm{~mL}$ of $\mathrm{Hg}$ (II) solution. The $\mathrm{pH}$ was adjusted to an optimum $\mathrm{pH}$, and the $\mathrm{Hg}$ (II) samples were collected at various time intervals $(0.16,1,2,3,5,10$ and $30 \mathrm{~min})$.

The selectivity of MIP and NIP was determined by studying the sorption of MIP and NIP towards $\mathrm{Hg}$ (II) ions against the competitive ions, that include $\mathrm{Pb}(\mathrm{II}), \mathrm{Cd}(\mathrm{II})$ and $\mathrm{Zn}$ (II). A solution of $10 \mathrm{~mL}$ containing $10 \mathrm{~mL} / \mathrm{L}$ of $\mathrm{Hg}(\mathrm{II})$ and the competitor ions were mixed together and treated with MIP and NIP (10 mg) at room temperature. The concentrations of the metal ions were measured by ICP-MS, and the binding capacity and distribution coefficient were calculated.

Similarly, the desorption of $\mathrm{Hg}(\mathrm{II})$ ions was studied by using $0.5 \%$ thiourea in $0.05 \mathrm{M} \mathrm{HCl}$ solution. Then, the MIP was dried and reused for the sorption of $\mathrm{Hg}(\mathrm{II})$. The $\mathrm{Hg}(\mathrm{II})$ ions' sorption-desorption procedure was repeated for 4 times using the same MIP inside the cartridge.

\subsection{Adsorption of Hg(II) Ions from Petroleum Oil Samples}

The sorption of $\mathrm{Hg}(\mathrm{II})$ ions on MIP from petroleum oil was studied by using the same SPE method. For that, the derivation of petroleum oil, that is the crude and sludge samples, was obtained from HG solution Sdn. Bhd, Malaysia.

\subsection{Statistical Analysis}

Data are presented as the mean $\pm \mathrm{SD}$ of 3 separate experiments, and the statistical analyses were performed using a one-way analysis of variance (ANOVA) method for multiple comparisons. A probability of $p<0.05$ was considered statistically significant and $p<0.01$ as highly statistical significant.

\section{Conclusions}

In this study, we developed a cysteine-complexed MIP to serve as a useful technique for the removal of heavy metal ions by using electrostatic and van der Waals chemistry between lone pair electron groups of cysteine and $\mathrm{Hg}$ (II) ions. The MIP of the cysteine complex prepared by the bulk polymerization method was thoroughly characterized by FTIR, FESEM and TGA for the bonding, morphology and thermal stability, respectively. The studies of the effect of $\mathrm{pH}$, dosage, adsorption isotherm, adsorption kinetics and selectivity parameters provide the information that our cysteine-complexed MIP is functioning effectively for the trapping of $\mathrm{Hg}(\mathrm{II})$ ions at a neutral $\mathrm{pH}$. Further, the sorption isotherm studies indicated that the Freundlich isotherm fits well for the adsorption of $\mathrm{Hg}(\mathrm{II})$ onto the MIP and is investigated to follow the pseudo-second order kinetics. Finally, our cysteine-complexed MIP also proved its selectivity efficiency towards $\mathrm{Hg}$ (II) ions when other competitive metal ions, such as $\mathrm{Cd}(\mathrm{II})$, $\mathrm{Zn}$ (II) and $\mathrm{Pb}$ (II), were present in the samples. In addition, its applicability for the real-time analysis of samples was confirmed when $94 \%$ of $\mathrm{Hg}$ (II) from sludge and $30 \%$ from crude oil samples were observed within a 2-min time interval. All of these results therefore confirm the promising behavior of our newly synthesized cysteine-complexed MIP towards the separation of toxic pollutants from crude and petroleum oils and other industrial wastes. 


\section{Acknowledgments}

The author would like to acknowledge the Ministry of Higher Education and Universiti Putra Malaysia for their financial support in the form of the Graduate Research Fellowship (GRF) and MyBrain15.

\section{Author Contributions}

All authors have contributed equally for the publication of this manuscript. Nor Ain Shahera Khairi conducted the experiment, collected and analyzed the data; Nor Azah Yusof and Abdul Halim Abdullah gave technical support and provided the conceptual advice, while Faruq Mohammad did the technical editing and helped until the final publication of the manuscript.

\section{Conflicts of Interest}

The authors declare no conflict of interest.

\section{References}

1. Risher, J.F.; Amler, S.N. Mercury exposure: evaluation and intervention the inappropriate use of chelating agents in the diagnosis and treatment of putative mercury poisoning. Neurotoxicology 2005, 26, 691-699.

2. Díez, S. Human health effects of methylmercury exposure. Rev. Environ. Contam. Toxicol. 2009, 198, 111-132.

3. Bose-O'Reilly, S.; McCarty, K.M.; Steckling, N.; Lettmeier, B. Mercury exposure and children's health. Curr. Probl. Pediatr. Adolesc. Health Care 2010, 40, 186-215.

4. Sondreal, E.A.; Benson, S.A.; Pavlish, J.H.; Ralston, N.V.C. An overview of air quality III: Mercury, trace elements, and particulate matter. Fuel Process. Technol. 2004, 85, 425-440.

5. U.S. Environmental Protection Agency. Mercury Study Report to Congress; EPA-452/R-97-003; Office of Air Quality Planning and Standards, Office of Research and Development, U.S. Government Printing Office: Washington, DC, USA, 1998.

6. Granite, E.J.; Pennline, H.W.; Hargis, R.A. Novel sorbents for mercury removal from flue gas. Ind. Eng. Chem. Res. 2000, 39, 1020-1029.

7. Wilhelm, S.M.; Liang, L.; Kirchgessner, D. Identification and properties of mercury species in crude oil. Energ. Fuel 2006, 20, 180-186.

8. Shafeeq, A.; Muhammad, A.; Sarfraz, W.; Toqeer, A.; Rashid, S.; Rafiq, M.K. Mercury removal techniques for industrial waste water. World Acad. Sci. Eng. Technol. 2012, 6, 12-26.

9. Reddy, K.S.; Shoaibi, A.A.; Srinivasakannan, C. Elemental mercury adsorption on sulfur-impregnated porous carbon-A review. Environ. Technol. 2014, 35, 18-26.

10. Wilhelm, S.M.; Bloom, N. Mercury in petroleum. Fuel Process. Technol. 2000, 63, 1-27.

11. Brüggemann, O.; Haupt, K.; Ye, L.; Yilmaz, E.; Mosbach, K. New configurations and applications of molecularly imprinted polymers. J. Chromatogr. A 2000, 889, 15-24.

12. Pichon, V.; Chapuis-Hugon, F. Role of molecularly imprinted polymers for selective determination of environmental pollutants-A review. Anal. Chim. Acta 2008, 622, 48-61. 
13. Koesdjojo, M.T.; Tennico, Y.H.; Remcho, V.T. Molecularly imprinted polymers as sorbents for separation and extractions. In Separation Science and Technology: HPLC Method Development for Pharmaceuticals; Ahuja, S., Rasmussen, H., Eds.; Academic Press: New Jersey, NJ, USA, 2007; Volume 8, pp. 479-503.

14. Owens, P.K.; Karlsson, L.; Lutz, E.S.M.; Andersson, L.I. Molecular imprinting for bio- and pharmaceutical analysis. Trends Anal. Chem. 1999, 18, 146-154.

15. Li, B.; Zhang, Y.; Ma, D.; Shi, Z.; Ma, S. Mercury nano-trap for effective and efficient removal of mercury(II) from aqueous solution. Nat. Commun. 2014, 5, 7.

16. Kumar, C.S.S.R.; Mohammad, F. Magnetic gold nanoshells: Stepwise changing of magnetism through stepwise biofunctionalization. J. Phys. Chem. Lett. 2010, 1, 3141-3146.

17. Yusof, N.A.; Rahman, S.K.A.; Hussein, M.A.; Ibrahim, N.A. Preparation and characterization of molecularly imprinted polymer as SPE sorbent for melamine isolation. Polymers 2013, 5, $1215-1228$.

18. Liu, Y.; Chang, X.; Yang, D.; Guo, Y.; Meng, S. Highly selective determination of inorganic mercury(II) after preconcentration with $\mathrm{Hg}(\mathrm{II})$-imprinted diazoaminobenzene-vinylpyridine copolymers. Anal. Chim. Acta 2005, 538, 85-91.

19. Wu, G.; Wang, Z.; Wang, J.; He, C. Hierarchically imprinted organic-inorganic hybrid sorbent for selective separation of mercury ion from aqueous solution. Anal. Chim. Acta 2007, 582, 304-310.

20. Dekhil, A.B.; Hannachi, Y.; Ghorbel, A.; Baubaker, T. Comparative study of the removal of cadmium from aqueos solution by low cost adsorbents. J. Environ. Sci. Technol. 2011, 4, 520-533.

21. Rao, M.M.; Reddy, D.H.K.K.; Venkateswarlu, P.; Seshaiah, K. Removal of mercury from aqueous solutions using activated carbon prepared from agricultural by-product/waste. J. Environ. Manag. 2009, 90, 634-643.

22. Umpleby, R.J.; Baxter, S.C.; Rampey, A.M.; Rushton, G.T.; Chen, Y.; Shimizu, K.D. Characterization of the heterogeneous binding site affinity distributions in molecularly imprinted polymers. J. Chromatogr. 2004, 804, 141-149.

23. García-Calzón, J.A.; Díaz-García, M.E. Characterization of binding sites in molecularly imprinted polymers. Sens. Actuators B 2007, 123, 1180-1194.

24. Ahmed, M.J.; Dhedan, S.K. Equilibrium isotherms and kinetics modeling of methylene blue adsorption on agricultural wastes-based activated carbons. Fluid Phase Equilib. 2012, 317, 9-14.

25. Ho, Y.S.; Mckay, G. Pseudo-second order model for sorption processes. Process. Biochem. 1999, 34, 451-465.

26. Tuzen, M.; Sari, A.; Mendil, D.; Soylak, M. Biosorptive removal of mercury(II) from aqueous solution using lichen (Xanthoparmelia conspersa) biomass: Kinetic and equilibrium studies. J. Hazard. Mater. 2009, 169, 263-270.

27. Bayramoglu, G.; Arica, M.Y. Synthesis of Cr(VI)-imprinted poly(4-vinyl pyridine-co-hydroxyethyl methacrylate) particles: Its adsorption propensity to Cr(VI). J. Hazard. Mater. 2011, 187, 213-221.

(C) 2015 by the authors; licensee MDPI, Basel, Switzerland. This article is an open access article distributed under the terms and conditions of the Creative Commons Attribution license (http://creativecommons.org/licenses/by/4.0/). 